\title{
Influence of Pulp, Sugar and Maltodextrin Addiction in the Formulation of Kiwi Jellies With Lemon Grass Tea
}

\author{
Sâmela L. Barros ${ }^{1}$, Newton C. Santos ${ }^{1}$, Raphael L. J. Almeida ${ }^{1}$, Semirames do N. Silva ${ }^{1}$, \\ Amanda P. S. Nascimento ${ }^{1}$, Renata D. Almeida ${ }^{1}$, Victor H. de A. Ribeiro ${ }^{1}$, Wilton P. Silva ${ }^{1}$, \\ Josivanda P. Gomes ${ }^{1}$, Vírgínia M. de A. Silva ${ }^{1}$, Tamires S. Pereira ${ }^{1}$, Ângela M. Santiago ${ }^{2}$ \& Márcia R. Luiz ${ }^{2}$ \\ ${ }^{1}$ Federal University of Campina Grande, Campina Grande, Brazil \\ ${ }^{2}$ Paraiba State University, Campina Grande, Brazil \\ Correspondence: Sâmela L. Barros, Federal University of Campina Grande, Campina Grande, Brazil. Tel: \\ 55-839-9856-2466. E-mail: samelaleal7@gmail.com
}

Received: June 1, 2019

Accepted: July 11, $2019 \quad$ Online Published: September 15, 2019

doi:10.5539/jas.v11n15p125

URL: https://doi.org/10.5539/jas.v11n15p125

\begin{abstract}
The jellies constitute an important alternative for the processing of fruits, adding greater economic and nutritional value. The objective of this study was to evaluate the effects of different concentrations of pulp, sugar and maltodextrin on the physical-chemical and textural characteristics of kiwifruit jelly with lemon grass tea. Factorial design $2^{3}$ was used with 3 replicates at the central point, resulting in 11 experiments with variation of sugar percentages (30, 40 and 50\%), pulp (50,60 and 70\%) and maltodextrin $(5,10$ and 15\%). Water content, moisture content, total soluble solids (TSS), total titratable acidity (TTA), ashes, $\mathrm{pH}$, reducing sugars, non-sugars were evaluated for the following physico-chemical parameters: reducers, total sugars, lipids and vitamin C. Regarding the texture profile, the following parameters were evaluated: hardness, cohesiveness, chewing, gummy and adhesiveness. It was found that among the analyzed variables, the ones that were considered as significant and/or predictive according to ANOVA and the F test were: (moisture, total solids, carbohydrates and vitamin C), through the graphs of the surfaces of responses observed that the percentage of pulp and maltodextrin used was proportional to the increase in moisture content, vitamin $\mathrm{C}$, total solids and carbohydrates. The G2 experiment presented the lowest values of moisture and water activity, and higher carbohydrate contents, total solids and cohesiveness, in which it was formulated with the sugar concentration $(-1)$ and pulp and maltodextrin $(+1)$. The development of kiwi jelly with lemon grass tea is an excellent alternative for the use of the raw material, since it is a product with high nutritional value, stability during storage and potential for consumer acceptance.
\end{abstract}

Keywords: Actinidia deliciosa, new products, texture

\section{Introduction}

The kiwi (Actinidia deliciosa) is a fruit that has great economic importance, mainly in China, Italy and New Zealand, that are its main producers. It has high content of vitamin $\mathrm{C}$ and bioactive compounds, such as phenolic compounds, insoluble fiber, carotenoids, flavonoids and minerals. The nutritional quality and TTAractive taste are responsible for the good acceptance of kiwi worldwide and despite the numerous qualities described above, kiwi fruit is highly perishable due to its sensitivity to mechanical damage and high water content, which makes it possible the development of microorganisms and the occurrence of biochemical reactions that cause their rapid deterioration and consequently many losses in the post-harvest stages (Lyu et al., 2018; Móran et al., 2018).

The purpose of the processing is to increase the stability of the product, to allow its storage for a long period of time, allowing its consumption in the off-season. Jellies constitute an important alternative for fruit processing and is defined as the product obtained from cooking fruits, pulp or juice, mixed with sugar, water and other optional raw materials such as pectin and acidulants. The stabilization of the jellies is obtained through the heat treatment applied, associated to the increase of the soluble solids content, increase of the acidity and decrease of the water content. These parameters are responsible for the inhibition of the growth of microorganisms and enzymatic activity, besides being of great importance for the texture, structure and general quality of fruit sweets, since the adequate gelation of pectins of high methoxylation occurs only in narrow bands of $\mathrm{pH}$ (2.8 to 3.5) and high sugar content ( 600 to $800 \mathrm{~g} / \mathrm{kg}$ ), making it possible to obtain a product with high added value, easy handling 
and greater stability. The final product must have a semi-solid consistency and be packaged in a way to guarantee its perfect preservation (Oliveira et al., 2014; Garrido et al., 2015; Sousa et al., 2015; Silva et al., 2018).

During the process of producing jellies, the heat treatment is applied until the desired solids content is reached by evaporation of the water. The concentration of the mixture enables the reduction of water activity, allowing greater microbiological stability to the product and reduction of the microbial load, which allows the increase of the shelf life. In addition to microbiological safety, other aspects of quality in the production of jellies, such as color, texture and physical and chemical parameters that may be affected during storage, should be considered, making it necessary to study the chemical and physical stability of new food products to optimize the process and obtain a product that is well accepted in the market and safe for the consumer (Oliveira et al., 2014).

Maltodextrin is a type of complex carbohydrate, classified as an oligosaccharide with a high glycemic index, low osmotic value and neutral taste, besides being highly soluble in water and easily absorbed by the body. For athletes, the ingestion of maltodextrin before, during and after exercise is very common because its consumption is associated with the rapid and significant increase in glycemia in healthy individuals, providing maintenance of blood glucose levels and avoiding a decrease in performance during the exercise associated with hypoglycemia, in addition to helping to increase muscle glycogen stores during intense and prolonged exercises (Cardoso et al., 2017).

In the food industry, maltodextrin is used in the production of various products and more recurringly it is used as adjuvant in the convective drying process or in the microencapsulation process in spray dryer drying. Maltodextrin has high emulsification capacity, low cost and gives the product greater stability, retention of volatile compounds and reduction of hygroscopicity (Carmo et al., 2015; Cardoso et al., 2017; Freitas et al., 2019).

The objective of the present study was to elaborate and evaluate kiwifruit jellies flavored with holy grass tea, checking the influence of the variables (pulp, sugar and maltodextrin) on their physico-chemical and textural properties, development of new products that meet consumer demand.

\section{Material and Methods}

For the accomplishment of this research, the fruits of kiwi cv. Hayward (Actinidia deliciosa) and lemon grass (Cymbopogon citratus) were purchased at the local commerce of the municipality of Campina Grande and conducted to the Laboratory of Storage and Processing of Agricultural Products, belonging to the Federal University of Campina Grande, Brazil.

The fruits were selected for uniformity and maturation stage. Initially the fruits were washed in running water and sanitized in sodium hypochlorite solution at $200 \mathrm{ppm}$ for $15 \mathrm{~min}$. Subsequently, the kiwifruit were peeled with a stainless steel knife and processed in a blender to obtain the pulp.

For the preparation of the lemon grass tea, the ratio 1:1 (lemon grass:water) was used, the water after boiling was placed on the lemon grass and allowed to infuse until the mixture cooled. Thereafter, the mixture was sieved and the tea obtained was used in the preparation of the jellies.

\subsection{Processing of Jellies}

The kiwi pulp was mixed with the crystal sugar and the maltodextrin, then the mixture was brought to the open pan cooking under heating with continuous manual stirring. To make gel formation possible in the formulations, $1 \%$ pectin with high methoxylation content was used, during cooking the same was added previously dissolved in the holy grass tea and the $\mathrm{pH}$ of the mixture was corrected to 3.2 by addition of citric acid.

When the jellies reached solids content higher than $65^{\circ} \mathrm{Brix}$, the cooking process was completed, then they were hot packed in pre-sterilized glass containers $\left(100{ }^{\circ} \mathrm{C}\right.$ for $\left.30 \mathrm{~min}\right)$ and stored under refrigeration at $5{ }^{\circ} \mathrm{C}$ until the moment of the analyzes.

\subsection{Physico-Chemical Analysis}

The jellies produced were submitted in triplicate, the following physical-chemical analysis: Moisture and total solids in a vacuum oven at $70{ }^{\circ} \mathrm{C}$ to constant weight; Ash by muffle incineration; Total protein content was quantified by the Micro-Kjeldahl method, which consisted of the determination of total nitrogen; Total Soluble Solids (SST) in refractometer; Titratable Total Acidity (TTA) determined by titration; Relationship SST/TTA (ratio); $\mathrm{pH}$ measured directly in digital potentiometer according to the methodology described by Brazil (2008); The lipid content was determined by the method of Bligh and Dyer (1959); The total carbohydrate content was calculated by difference to obtain $100 \%$ of the total composition (FAO, 2003); Water activity $\left(\mathrm{a}_{\mathrm{w}}\right)$ was 
determined using the Decagon ${ }^{\circledR}$ Aqualab CX-2T device at $25{ }^{\circ} \mathrm{C}$. Non-reducing sugars (NR), reducing sugars (RS) and total sugars (TA) were determined by the method described by Lane and Eynon (1934); the content of ascorbic acid (Vitamin C) was determined according to the methodology proposed by Adolfo Luttz Institute (Brazil, 2008) and the results expressed in $\mathrm{mg}$ of ascorbic acid/100 g sample.

\subsection{Texture Profile}

To obtain the parameters of the jelly's instrumental texture profiles, the TPA test in the TAXT Plus Texturometer (Stable Micro Systems) equipped with the ExponentStable Micro Systems software, using the P/36R probe, was used. In the texture profile, the studied TTAributes were firmness, cohesiveness, adhesiveness, guminess and chewing.

\subsection{Statistic Analyzes}

Kiwi jellies were processed using the factorial design method 23 with 3 replicates at the central point, resulting in a matrix with 11 experiments (Table 1), in order to evaluate the influence of the independent variables (concentrations of sugar, pulp and maltodextrin) on the variables responses (physical-chemical and textural characteristics, as well as the interactions between them). The effect of the independent variables on the dependent variables was evaluated by statistical analysis, using the Statistica ${ }^{\circledR}$ software version 7.0.

Table 1. Planning matrix for the elaboration of kiwifruit jams with sacred grass tea, with their respective independent variables and their actual and codified levels

\begin{tabular}{llll}
\hline \multirow{2}{*}{ Experiments } & \multicolumn{3}{c}{ Independent variables } \\
\cline { 2 - 4 } & Sugar $(\%)$ & Pulp $(\%)$ & Maltodextrin (\%) \\
\hline $\mathrm{G}_{1}$ & $+1(50)$ & $+1(70)$ & $+1(15)$ \\
$\mathrm{G}_{2}$ & $-1(30)$ & $+1(70)$ & $+1(15)$ \\
$\mathrm{G}_{3}$ & $+1(50)$ & $-1(50)$ & $+1(15)$ \\
$\mathrm{G}_{4}$ & $-1(30)$ & $-1(50)$ & $+1(15)$ \\
$\mathrm{G}_{5}$ & $+1(50)$ & $+1(70)$ & $-1(5)$ \\
$\mathrm{G}_{6}$ & $-1(30)$ & $+1(70)$ & $-1(5)$ \\
$\mathrm{G}_{7}$ & $+1(50)$ & $-1(50)$ & $-1(5)$ \\
$\mathrm{G}_{8}$ & $-1(30)$ & $-1(50)$ & $-1(5)$ \\
$\mathrm{G}^{9}(\mathrm{C})$ & $0(40)$ & $0(60)$ & $0(10)$ \\
$\mathrm{G}^{10}(\mathrm{C})$ & $0(40)$ & $0(60)$ & $0(10)$ \\
$\mathrm{G}^{11}(\mathrm{C})$ & $0(40)$ & $0(60)$ & $0(10)$ \\
\hline
\end{tabular}

Note. G1, G2 ... G11: Jelly kiwi with lemon grass tea; (C) Central point.

\section{Results and Discussion}

Table 2 presents the mean values of the variable responses for the physical-chemical characteristics of kiwifruit jelly with lemon grass tea. 
Table 2. Results of physical-chemical analysis of kiwifruit jelly with lemon grass tea

\begin{tabular}{|c|c|c|c|c|c|c|c|c|}
\hline Experiments & Moisture content $(\%)$ & $a_{w}$ & TTA ( $\%$ citric acid) & $\mathrm{pH}$ & SST $\left({ }^{\circ}\right.$ Brix $)$ & Ratio & ANR $(\%)$ & $\operatorname{AR}(\%)$ \\
\hline $\mathrm{G}_{1}$ & 35.45 & 0.829 & 0.617 & 3.59 & 63.33 & 97.75 & 46.69 & 36.31 \\
\hline $\mathrm{G}_{2}$ & 32.55 & 0.805 & 0.495 & 3.49 & 62.67 & 104.70 & 44.69 & 34.08 \\
\hline $\mathrm{G}_{3}$ & 35.81 & 0.822 & 0.682 & 3.47 & 64.33 & 79.74 & 40.57 & 29.55 \\
\hline $\mathrm{G}_{4}$ & 34.49 & 0.815 & 0.649 & 3.50 & 68.33 & 105.24 & 38.44 & 28.95 \\
\hline $\mathrm{G}_{5}$ & 35.11 & 0.819 & 0.637 & 3.56 & 65.33 & 87.00 & 44.91 & 35.29 \\
\hline $\mathrm{G}_{6}$ & 33.64 & 0.818 & 0.540 & 3.57 & 66.33 & 117.31 & 44.17 & 21.91 \\
\hline $\mathrm{G}_{7}$ & 36.79 & 0.857 & 0.862 & 3.53 & 63.33 & 61.91 & 39.69 & 27.91 \\
\hline $\mathrm{G}_{8}$ & 33.90 & 0.818 & 0.655 & 3.51 & 64.33 & 105.24 & 40.18 & 25.80 \\
\hline $\mathrm{G}_{9}$ & 34.57 & 0.809 & 0.682 & 3.50 & 72.33 & 98.30 & 39.76 & 22.15 \\
\hline $\mathrm{G}_{10}$ & 34.62 & 0.809 & 0.696 & 3.49 & 72.67 & 104.38 & 40.31 & 21.23 \\
\hline $\mathrm{G}_{11}$ & 34.34 & 0.807 & 0.693 & 3.49 & 72.33 & 104.45 & 40.35 & 21.17 \\
\hline Experiments & AT $(\%)$ & ST (\%) & Proteins (\%) & Lipidis (\%) & Carbohydrates (\%) & Ashes $(\%)$ & Vitamin $C^{1}$ & \\
\hline $\mathrm{G}_{1}$ & 83.00 & 64.55 & 0.25 & 0.35 & 63.64 & 0.31 & 20.24 & \\
\hline $\mathrm{G}_{2}$ & 79.98 & 67.45 & 0.23 & 0.29 & 66.61 & 0.32 & 14.04 & \\
\hline $\mathrm{G}_{3}$ & 70.13 & 64.19 & 0.24 & 0.36 & 63.23 & 0.36 & 18.77 & \\
\hline $\mathrm{G}_{4}$ & 66.36 & 65.51 & 0.20 & 0.29 & 64.71 & 0.31 & 20.03 & \\
\hline $\mathrm{G}_{5}$ & 78.99 & 64.89 & 0.22 & 0.37 & 63.98 & 0.33 & 17.68 & \\
\hline $\mathrm{G}_{6}$ & 76.07 & 66.36 & 0.24 & 0.28 & 65.56 & 0.29 & 15.54 & \\
\hline $\mathrm{G}_{7}$ & 68.64 & 63.21 & 0.22 & 0.36 & 62.25 & 0.37 & 20.46 & \\
\hline $\mathrm{G}_{8}$ & 65.98 & 66.10 & 0.24 & 0.25 & 65.32 & 0.29 & 18.05 & \\
\hline $\mathrm{G}_{9}$ & 61.91 & 65.43 & 0.25 & 0.17 & 64.63 & 0.38 & 17.84 & \\
\hline $\mathrm{G}_{10}$ & 61.54 & 65.38 & 0.24 & 0.17 & 64.58 & 0.39 & 17.92 & \\
\hline $\mathrm{G}_{11}$ & 61.52 & 65.66 & 0.24 & 0.17 & 64.86 & 0.40 & 17.82 & \\
\hline
\end{tabular}

Note. ${ }^{1}$ Results expressed in mg of ascorbic acid/100 g sample.

The moisture content of kiwifruit jams with lemon grass tea ranged from 32.55 (G2) to $36.79 \%$ (G7), lower values of this parameter were observed in the experiments at the lower level (-1) of pulp and maltodextrin. It can also be stated that the values of moisture content obtained are presented according to the quality standard established by the Brazilian legislation (Brazil, 1978), which indicates that the maximum moisture content for fruit jellies should be lower to $38 \%$. In relation to the water activity $\left(a_{w}\right)$ there was a variation of 0.805 to 0.857 , this parameter presented a behavior similar to that observed with respect to the moisture content, in which lower values were observed in samples containing less percentage of pulp.

According to Barros et al. (2019a), reduced values of moisture content and water activity indicate higher stability of the product during storage and foods that have a moisture content of more than $20 \%$ and a higher water activity of 0.60 are subject to deterioration processes caused by molds and yeasts.

Titratable total acidity (TFA) values expressed as citric acid ranged from 0.495 (G2) to $0.862 \%$ (G7). These percentages are similar to those observed by Oliveira et al. (2019) in achachairu jellies $(0.500$ to $0.690 \%)$ and by Barros et al. (2019a) in pineapple jellies with cinnamon ( 0.47 to $0.99 \%$ citric acid), the authors stated that although the legislation does not indicate the range of TTA suitable for jellies, values lower than $0.3 \%$ or higher than $0.8 \%$ may cause loss of elasticity of the jelly due to pectin hydrolysis.

The hydrogenation potential ( $\mathrm{pH}$ ) of the samples varied from 3.47 (G3) to 3.59 (G1), the samples were adequate to Brazilian legislation for fruit products (Brazil, 2005), which establishes that the maximum limit for this parameter is 4.5. Teles et al. (2017) when developing graviola jelly with pepper obtained $\mathrm{pH}$ values close to the present study (3.69 to 3.93), however, Garcia et al. (2017) stated that the ideal $\mathrm{pH}$ range for gel formation to occur is 3.0 to 3.2. While for Bolzan and Pereira (2017), the ideal pH range for gel formation is 3.0 to 3.5 .

The jellies presented total soluble solids content (TSS) ranging from 62.67 (G2) to $72.67^{\circ}$ Brix (G10) and are in accordance with the legislation, which establishes a minimum SST content for common $62{ }^{\circ}$ Brix jelly (Brazil, 1978 ). Values similar to those were obtained by Oliveira et al. (2016) in oat-enriched orange jellies (62 to $66^{\circ}$ Brix). High levels of total soluble solids (TSS) associated to low water content and $\mathrm{pH}$ are capable of minimizing the development of microorganisms and may favor the formation of crystallization of sucrose, which is responsible for improving the viscosity and texture of the product (Oliveira et al., 2019; Barros et al., 2019a). 
Regarding the Ratio parameter, a variation from 61.91 (G7) to 117.31 (G6) was observed, indicating that the G6 sample has a higher degree of sweetness. For, according to Sousa et al. (2018), the Ratio parameter is a technological index used to indicate the relationship between SST and TTA of the product and is able to evaluate the taste of the product, also indicating the degree of sweetness.

The content of reducing sugars varied from 21.17 (G11) to $36.31 \%$ (G1) and the non-reducing sugars varied from 38.44 (G4) to $46.69 \%(\mathrm{G} 1)$, as expected, the highest values were verified in the samples with the highest percentage of sugar. The total sugars obtained in the present study presented a variation from 61.52 (G11) to $83 \%$ of glucose (G1), values higher than that observed by Martins el al. (2015) in mixed jelly of pineapple peel and peach pulp (44.56\%).

In relation to the total solids content, a variation from $63.21(\mathrm{G} 7)$ to $67.45 \%(\mathrm{G} 2)$ was observed, values obtained were directly proportional to the percentage of maltodextrin and kiwi pulp used in the formulations, similar values were obtained by Barros et al. (2019b) in blackberry jelly.

Kiwifruit jams with low-salt tea have low protein values $(0.20$ to $0.25 \%)$ and are slightly lower than those observed by Silva et al. (2018) in sweet orange jelly ( 0.58 to $0.62 \%)$. The jellies also presented low lipid content ( 0.17 to $0.37 \%$ ), being slightly higher than that found by Souza et al. (2015) in blackberry jellies ( 0.09 to $0.15 \%)$. Regarding the carbohydrate content, a variation of 62.25 to $66.61 \%$ was observed, values similar to those observed by Souza et al. (2018) in umbu jelly and mango (67.29 to $70.03 \%)$.

As regards ash content, low values $(0.29$ to $0.40 \%)$ were observed, as verified by Oliveira et al. (2019) in achachairu jelly $(0.28$ to $0.80 \%$ ). The vitamin $\mathrm{C}$ content (ascorbic acid) ranged from 14.04 to $20.46 \mathrm{mg}$. This parameter was found to correlate with the percentage of sugar and maltodextrin used. These values are similar to those quantified by Azevedo et al. (2018) in manuring jellies (7.40 to $14.19 \mathrm{mg}$ ).

Table 3 presents the mean values of the variable responses for the textural characteristics of kiwifruit jelly with lemon grass tea.

Table 3. Results of the texture profile of kiwifruit jelly with lemon grass tea

\begin{tabular}{llllll}
\hline Experiments & Firmness (N) & Cohesiveness (N.m) & Adhesiveness (N.m) & Gumminess (N) & Chewiness $(\mathrm{J})$ \\
\hline $\mathrm{G}_{1}$ & 0.263 & 0.8404 & 0.285 & 0.2210 & 0.2210 \\
$\mathrm{G}_{2}$ & 0.228 & 0.8876 & 0.184 & 0.2023 & 0.2024 \\
$\mathrm{G}_{3}$ & 0.216 & 0.8769 & 0.113 & 0.1894 & 0.1894 \\
$\mathrm{G}_{4}$ & 0.247 & 0.8457 & 0.268 & 0.2089 & 0.2089 \\
$\mathrm{G}_{5}$ & 0.228 & 0.8833 & 0.185 & 0.2036 & 0.2037 \\
$\mathrm{G}_{6}$ & 0.224 & 0.8838 & 0.179 & 0.1979 & 0.1980 \\
$\mathrm{G}_{7}$ & 0.256 & 0.8332 & 0.302 & 0.2133 & 0.2133 \\
$\mathrm{G}_{8}$ & 0.233 & 0.8594 & 0.229 & 0.2002 & 0.2002 \\
$\mathrm{G}_{9}$ & 0.242 & 0.8527 & 0.251 & 0.2063 & 0.2063 \\
$\mathrm{G}_{10}$ & 0.231 & 0.8667 & 0.223 & 0.2002 & 0.2002 \\
$\mathrm{G}_{11}$ & 0.234 & 0.8607 & 0.231 & 0.2014 & 0.2014 \\
\hline
\end{tabular}

It can be seen from Table 3 that the firmness parameter presented a variation from 0.216 to $0.263 \mathrm{~N}$, the highest value obtained for the sample (G1). According to Garrido et al. (2015), firmness is defined as the force required to reach a given deformation, in the context of sensory analysis, represents the force required to compress the food between the molars at the first bite.

With respect to cohesiveness, small variations $(0.8404$ to $0.8933 \mathrm{~N} . \mathrm{m})$ were observed, in which the highest value was verified in sample G5. Besbes et al. (2009), when evaluating the cohesiveness of the date jelly, obtained values ranging from 0.51 to 0.77 N.m. According to Atallah and Morsy (2017), this parameter is often discussed in terms of adhesion forces and is responsible for the deformation occurring in the material prior to rupture, indicating its structural integrity.

The samples presented a variation from 0.113 (G3) to 0.302 N.m (G7) in the adhesiveness parameter, values similar to that obtained by Abid et al. (2018) in pomegranate jellies using different types of gelling agents (0.158 to 0.807 N.m). According to Guiné et al. (2015), adhesiveness is the force required to remove the material adhering to a specific surface and during food intake corresponds to adherence to the lips, mouth and teeth. 
The guminess of the jellies varied from 0.189 (G3) to $0.221 \mathrm{~N}$ (G1), similar values were observed by Curi et al. (2017) in physalis jellies (0.033 to $0.476 \mathrm{~N}$ ). For Bolzan and Pereira, (2017), gum is a parameter associated with firmness and cohesiveness, its variation being the reflection of these.

Superior chewability value was obtained in the formulation G1 $(0.221 \mathrm{~N})$, similar to that obtained by Curi et al. (2018) in physalis jams with brie cheese $(0.08$ to $0.58 \mathrm{~N})$. According to Curi et al. (2017) chewability is the parameter that represents the energy needed to chew a solid food to the point of ingestion. Therefore, it can be stated that the G1 sample has greater resistance to chewing when compared to the others.

Several factors can be associated with the variation in texture between kiwifruit jams with lemon grass, such as the percentage of raw materials (sugar, kiwi pulp and maltodextrin) and chemical parameters such as $\mathrm{pH}$, acidity and humidity (Curi et al., 2018).

Table 4 shows the analysis of variance (ANOVA) and the $\mathrm{F}$ test with $95 \%$ confidence only for the variables that were significant and/or predictive (moisture, vitamin C, total solids and carbohydrates) in the processing of kiwi jelly with tea of lemon grass.

Table 4. Analysis of variance (ANOVA) for moisture, total solids, carbohydrates and vitamin C of kiwifruit jelly with holy grass tea

\begin{tabular}{|c|c|c|c|c|c|c|c|}
\hline Source of variation & Quadratic sum & DF & Average Quadratic & Fcal & Ftab & Fcalculated/Ftabulated & $\mathrm{R}^{2}$ \\
\hline \multicolumn{8}{|l|}{ Moisture } \\
\hline Regression & 12.735 & 7 & 1.819 & $39.24^{(1)}$ & $6.16^{(3)}$ & 6.37 & 98.92 \\
\hline Waste & 0.1391 & 3 & 0.0463 & & & & \\
\hline Lack of adjustment & 0.0922 & 1 & 0.0921 & $3.93^{(2)}$ & $19^{(4)}$ & 0.21 & \\
\hline Pure error & 0.0469 & 2 & 0.0234 & & & & \\
\hline Total & 12.874 & 10 & & & & & \\
\hline \multicolumn{8}{|l|}{ Total solids } \\
\hline Regression & 12.734 & 7 & 1.819 & $39.241^{(1)}$ & $6.16^{(3)}$ & 6.37 & 98.92 \\
\hline Waste & 0.1391 & 3 & 0.0463 & & & & \\
\hline Lack of adjustment & 0.0922 & 1 & 0.0921 & $3.931^{(2)}$ & $19^{(4)}$ & 0.21 & \\
\hline Pure error & 0.0469 & 2 & 0.0234 & & & & \\
\hline Total & 12.874 & 10 & & & & & \\
\hline \multicolumn{8}{|l|}{ Carbohydrates } \\
\hline Regression & 13.890 & 7 & 1.984 & $27.524^{(1)}$ & $6.16^{(3)}$ & 4.47 & 99.69 \\
\hline Waste & 0.2162 & 3 & 0.0721 & & & & \\
\hline Lack of adjustment & 0.1718 & 1 & 0.1718 & $7.736^{(2)}$ & $19^{(4)}$ & 0.41 & \\
\hline Pure error & 0.0443 & 2 & 0.0222 & & & & \\
\hline Total & 14.106 & 10 & & & & & \\
\hline \multicolumn{8}{|l|}{ Vitamin $C$} \\
\hline Regression & 37.575 & 7 & 5.3678 & $119.34^{1)}$ & $6.16^{(3)}$ & 19.373 & 99.64 \\
\hline Waste & 0.1349 & 3 & 0.0449 & & & & \\
\hline Lack of adjustment & 0.1287 & 1 & 0.1287 & $41.39^{(2)}$ & $19^{(4)}$ & 2.18 & \\
\hline Pure error & 0.0062 & 2 & 0.0031 & & & & \\
\hline Total & 37.709 & 10 & & & & & \\
\hline
\end{tabular}

Note. (1) MS Regression/MS Residue; (2) MS No adjustment/MS Pure Error; (3) F95\%, 7.3; (4) F95\%, 1.2.

From the analysis of the results obtained with respect to the parameters of moisture, vitamin C, total solids and carbohydrates, it was verified that the coefficients of determination were superior to $98 \%$, indicating a better fit to the experimental data. For all the studied parameters, the calculated $\mathrm{F}$ was superior to the $\mathrm{F}$ tabulated for the regression. The inverse occurred for the lack of adjustment, except for the parameter of vitamin C. These data show the statistical significance of the models.

The individual effects of the independent variables (sugar, pulp and maltodextrin) as well as the interaction between them on the response variables (physical, chemical and textural analysis) presented a statistically significant model $(\mathrm{Fc} \geq \mathrm{Ftab})$. It can be verified in the pareto diagrams (Figure 1) the factors that had the greatest influence on the processing of the jelly. 


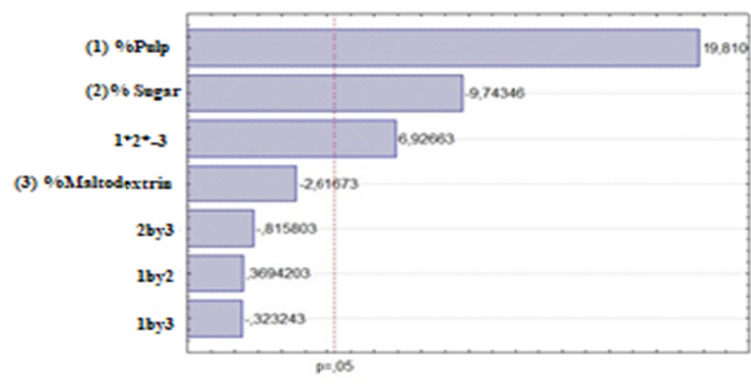

(a)

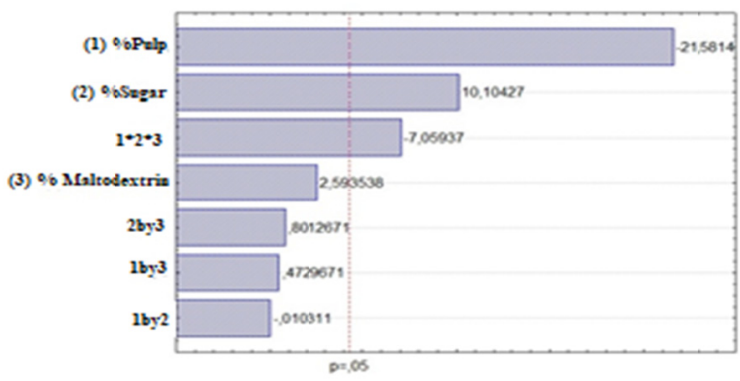

(c)

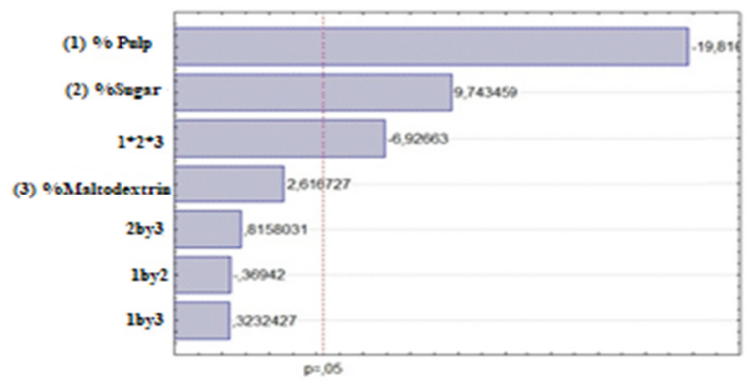

(b)

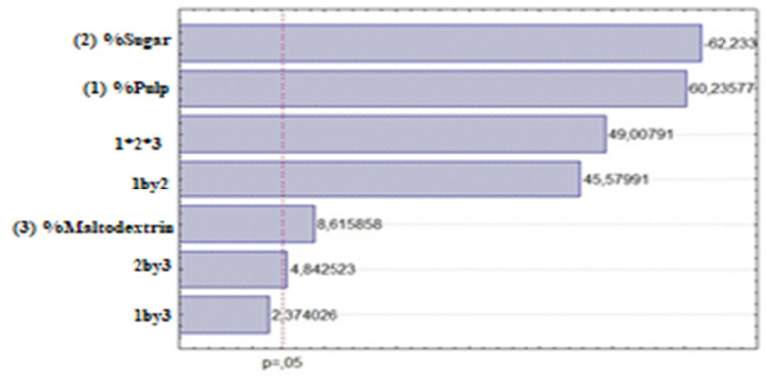

(d)

Figure 1. Pareto diagram for influence of sugar, pulp and maltodextrin concentration factors for the parameters: a) Moisture; b) Total solids; c) Carbohydrates; d) Vitamin C

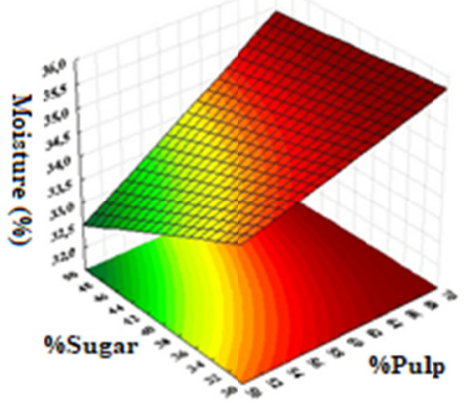

(a)

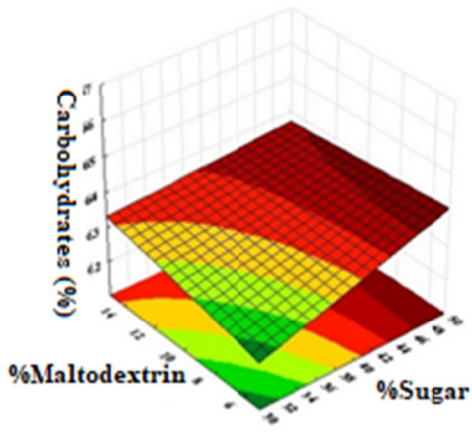

(c)

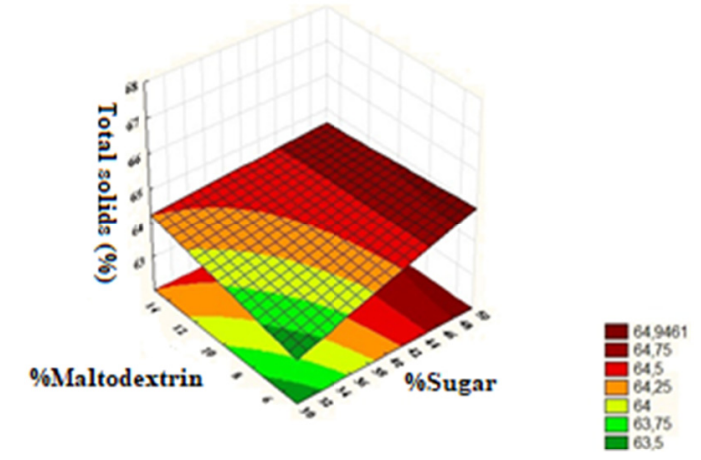

(b)

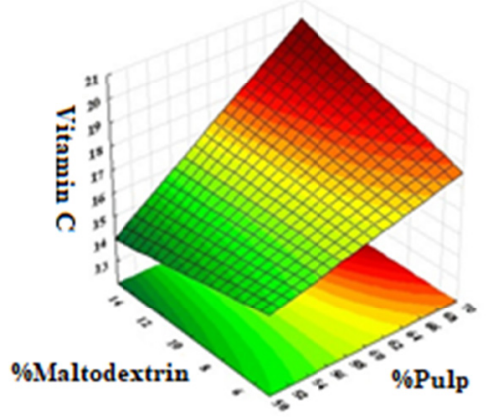

(d)

Figure 2. Response surfaces for the parameters of: a) moisture; b) total solids; c) carbohydrates; and d) vitamin C of the kiwifruit jelly with lemon grass, according to the percentages of sugar, pulp and maltodextrin 
From the pareto graphs with a significance level of $95 \%$, it was possible to observe that the percentage of sugar, pulp and the interaction between the percentage of sugar, pulp and maltodextrin were the factors that most influenced significantly the variables responses (moisture, total solids, carbohydrates and vitamin C). It is also verified that the percentage of maltodextrin only showed significant effect for the content of vitamin C.

The response surfaces obtained for the physical and chemical analyzes (response variables) presenting statistically significant models $(\mathrm{Fc} \geq \mathrm{Ftab})$ are represented in Figure 2 .

According to the graphs of the response surfaces, it is possible to infer that as the percentage variables of pulp and maltodextrin increase, parameters of moisture, total solids, carbohydrates and vitamin $\mathrm{C}$ tend to grow.

\section{Conclusion}

Through the present study, it was verified the viability of the use of kiwi and lemon grass in the elaboration of jelly, which is a product of high nutritional quality. It was verified that all the samples are in agreement with the standards of quality established by the Brazilian legislation, presenting in this way potential of commercialization. The independent variables that most influenced the formulation of the jellies were: percentage of sugar, pulp and the interaction between the percentage of sugar, pulp and maltodextrin. It was verified that the increase in the percentage of pulp and maltodextrin, provided the increase of moisture content, total solids, carbohydrates and vitamin C. The experiment G2 presented the lowest values of moisture and water activity, and higher carbohydrate contents, solids total and cohesiveness, in which it was formulated with the sugar concentration (-1) and pulp and maltodextrin $(+1)$.

\section{References}

Abid, M., Yaich, H., Hidouri, H., Attia, H., \& Ayadi, M. A. (2018). Effect of substituted gelling agents from pomegranate peel on colour,textural and sensory properties of pomegranate jam. Food Chemistry, 239, 1047-1054. https://doi.org/10.1016/j.foodchem.2017.07.006

Atallah, A. A., \& Morsy, K. M. (2017). Effect of Incorporating Royal Jelly and Bee Pollen Grains on Texture and Microstructure Profile of Probiotic Yoghurt. Journal of Food Processing and Technology, 8(9), 1-4.

Azevedo, L. M. F., Lucena, E. M. P., Bonilla, O. H., Silveira, M. R. S., \& Silva Júnior, A. (2018). Physical, chemical, microbiological and sensory carachterization of Manipuça jellies for municipal school meals of Fortaleza-CE. Brazilian Journal of Fruit Growing, 40(1), 1-7. https://doi.org/10.1590/0100-29452018728

Barros, S. L., Santos, N. C., Almeida, R. L. J., Nascimento, A. P. S., \& Silva, V. M. A. (2019). Quality parameters in blackberries jellies (Rubus sp.). Food Hygiene, 33, 1487-1492.

Barrosa, S. L., Silva, W. P., Figueiredo, R. M. F., Araujo, T. J., Santos, N. C., \& Gomes, J. P. G. (2019). Effect of the addition of different types of sugar on the quality of jelly made with pineapple and cinnamon. Magazine Principia, 45, 1-8.

Besbes, S., Drira, L., Blecker, C., Deroanne, C., \& Ttaia, H. (2009). Adding value to hard date (Phoenix dactylifera L.): Compositional, functional and sensory characteristics of date jam. Food Chemistry, 112(2), 406-411. https://doi.org/10.1016/j.foodchem.2008.05.093

Bligh, E. G., \& Dyer, W. J. (1959). A rapid method of total lipid and purifi cation. Canadian Journal of Biochemistry Physiology, 37(1), 911-917. https://doi.org/10.1139/y59-099

Bolzan, A. B., \& Pereira, E. A. (2017). Elaboração e caracterização de doce cremoso de caqui com adição de sementes da araucária. Brazilian Journal of Food Technology, 20, 1-11. https://doi.org/10.1590/ $1981-6723.6116$

Brazil, Adolfo Lutz Institute. (2008). Physical-chemical methods for food analysis (4th ed., Vol. 1, p. 1020). São Paulo: Adolfo Lutz Institute.

Brazil, Ministry of Health, Health Surveillance Secretariat. (1978). Defines terms on fruit jelly. Official Journal of the Federative Republic of Brazil, Brasília.

Brazil, Ministry of Health, National Health Surveillance Agency. (2005). Technical regulation for vegetable products, fruit products and edible mushrooms. Resolution of the Collegiate Board of Directors (No. 27). Official Gazette of the Federative Republic of Brazil, Brasília.

Cardoso, M., Seabra, T. T. P., \& Souza, E. B. (2017). Dextrose, Maltodextrin and Waxy Maize: Main differences in composition, mechanism of action and recommendations for sports performance. UniFOA Notebooks, 33, 101-109. 
Carmo, E. L., Fernandes, R. V. B., \& Borges, S. V. (2015). Microencapsulação por spray drying, novos biopolímeros e aplicações na tecnologia de alimentos. Journal of Chemical Engineering and Chemistry, 1(2), 30-44. https://doi.org/10.18540/2446941601022015030

Curi, P. N., Carvalho, C. S., Salgado, D. L., Pio, R., Paqual, M., Souza, F. B. M., \& Souza, V. R. (2017). Influence of different types of sugars in physalis jellies. Food and Science Technology, 37(3), 349-355. https://doi.org/10.1590/1678-457x.08816

Curi, P. N., Carvalho, C. S., Salgado, D. L., Pio, R., Silva, D. F., Pinheiro, A. C. M., \& Souza, V. R. (2017). Characterization of different native American physalis species and evaluation of their processing potential as jelly in combination with brie-type cheese. Food Science and Technology, 38(1), 112-119. https://doi.org/10.1590/1678-457x.01317

FAO (Food and Agriculture Organization of the United Nations). (2003). Food Energy: Methods of Analysis and Conversion Factors. Report of a Technical Workshop (Food and Nutrition Paper Volume 77). FAO: Rome, Italy.

Freitas, E. F. M., Lopes, L. L., Alves, S. M. F., \& Campos, A. J. (2019). Effect of maltodextrin on the atomized 'Pearl' pineapple pulp juice. Journal of Agricultural Sciences, 42(1), 275-282. https://doi.org/10.19084/ RCA18056

Garcia, L. G. C., Guimarães, W. F., Rodovalho, E. C., Peres, N. R. A. A., Becker, F. S., \& Damiani, C. (2017). Buriti jelly (Mauritia flexuosa): Adding value to the fruits of the Brazilian cerrado. Brazilian Journal of Food Technology, 20, 1-5. https://doi.org/10.1590/1981-6723.4316

Garrido, J. I., Lozano, J. E., \& Genovese, D. B. (2015). Effect of formulation variables on rheology, texture, colour, andacceptability of apple jelly: Modelling and optimization J.I. Food Science and Technology, 62(1), 325-332. https://doi.org/10.1016/j.lwt.2014.07.010

Guiné, R. P. F., Correia, P. M. R., \& Correia, A. C. (2015). Comparative evaluation of Portuguese goat and sheep cheeses. Millenium, 49, 111-130. https://doi.org/10.29352/mill0201.04.00037

Lane, J. H., \& Eynon, L. (1934). Determination of reducing sugars by Felhling's solution with methylene blue indicador (p. 8). Normam Rodge.

Lyu, X., Peng, X., Wang, S., Yang, B., Wang, X., Yang, H., ... Xia, X. (2018). Quality and consumer acceptance of radio frequency and traditional heat pasteurised kiwi puree during storage. International Journal of Food Science and Technology, 53, 209-218. https://doi.org/10.1111/ijfs.13575

Martins, J. J. A., Oliveira, E. N. A., Rocha, A. P. T., \& Santos, D. C. (2015). Stability of cashew jellies during storage under environmental conditions. Comunicata Scientiae, 6(2), 164-173.

Morán, F. E., Marco, E. N., Escrich, A., Barbé, S., \& López, M. M. (2018). Biodiversity and Biogeography of Three Pseudomonas syringae Pathovars which Affect Kiwi Fruit Cultivation. Journal Online Biodiversity, $1(1), 1-3$.

Oliveira, C. F. D., Pinto, E. G., Tomé, A. C., Quintana, R. C., \& Dias, B. F. (2016). Development and characterization of orange jelly enriched with oats. Journal of Neotropical Agriculture, 3(3), $20-23$. https://doi.org/10.32404/rean.v3i3.1203

Oliveira, E. N. A., Santos, D. C., Rocha, A. P. T., \& Gomes, J. P. (2014). Development, characterization and stability of traditional umbu-cajá jelly. Brazilian Journal of Fruit Growing, 36(3), 640-651.

Oliveira, K. D. C., Silva, S. S., Loss, R. A., \& Guedes, S. E. F. (2019). Sensory and physical-chemical analysis of achachairu jelly (Garcinia humillis). Food and Nutritional Safety, 26, 1-10. https://doi.org/10.20396/ san.v26i0.8653566

Silva, V. M., Campos, R. P., Borsato, A. V., Candido, C. J, \& Donadon, J.R. (2018). Bocaiuva jelly: Preparation, physicochemical and sensory evaluation. Brazilian Journal of Fruit Growing, 40(5), 1-9.

Silva, V. M., Campos, R. P., Borsato, A. V., Candido, C. J., \& Donadon, J. R. (2018). Bocaiuva jelly: Preparation, physicochemical and sensory evaluation. Brazilian Journal of Fruit Growing, 40(5), 1-9. https://doi.org/10.1590/0100-29452018846

Sousa, K. S. M., Figueirêdo, R. M. F., Queiroz, A. J. M., \& Fernandes, T. K. S. (2015). Production and characterization of powdered atom pulp. Brazilian Journal of Fruit Culture Jaboticabal, 37(3), 718-728. https://doi.org/10.1590/0100-2945-135/14 
Sousa, S. F., Silva, F. B., Araújo, A. C., \& Gomes, J. P. (2018). Determination of physical and physical-chemical properties of Rubimel cultivar peaches. Brazilian Journal of Agroindustrial Technology, 12(2), 2627-2644.

Souza, A. V., Rodrigues, R. J., Gomes, E. P., Gomes, G. P., \& Vieites, R. L. (2015). Bromatological characterization of blackberries fruits and jellies. Brazilian Journal of Fruit Growing, 37(1), 13-19. https://doi.org/10.1590/0100-2945-037/14

Souza, H. R. S., Santos, A. M., Ferreira, I. M., Silva, A. M. O., Nunes, T. P., \& Carvalho, M. G. (2018). Elaboration and evaluation of the quality of umbu jelly (Spondias tuberosa Arr. C.) and mangaba (Hancornia speciosa G.) with functional claim. Food and Nutritional Security, 25(3), 104-113. https://doi.org/10.20396/san.v25i3.8652496

Teles, A. C. M., Pinto, E. G., Santos, J. R., Oliveira, C. F. D., \& Soares, D. S. B. (2017). Development and physical-chemical characterization of common and extra jelly and soursop with pepper. Neotropical Agriculture Magazine, 4(1), 72-77. https://doi.org/10.32404/rean.v4i1.1341

\section{Copyrights}

Copyright for this article is retained by the author(s), with first publication rights granted to the journal.

This is an open-access article distributed under the terms and conditions of the Creative Commons Attribution license (http://creativecommons.org/licenses/by/4.0/). 